Proceedings

\title{
Alternative Grain Crops: Introducing the Kabog Millet from the Philippines as a Functional Food Ingredient ${ }^{+}$
}

\author{
Joan Oñate Narciso* and Laura M. Nyström
}

Citation: Narciso, J.O.; Nyström, L.M. Alternative Grain Crops: Introducing the Kabog Millet from the Philippines as a Functional Food Ingredient. 2021, 70, 92. https:// doi.org/10.3390/foods_2020-07740

Published: 10 November 2020

Publisher's Note: MDPI stays neutral with regard to jurisdictional claims in published maps and institutional affiliations.

Copyright: (c) 2020 by the authors. Licensee MDPI, Basel, Switzerland. This article is an open access article distributed under the terms and conditions of the Creative Commons Attribution (CC BY) license (http://creativecommons.org/licenses/by/4.0/).
Laboratory of Food Biochemistry, Institute of Food, Nutrition and Health, Department of Health Sciences and Technology, ETH Zurich, Schmelzbergstrasse 9, CH-8092 Zurich, Switzerland; laura.nystroem@hest.ethz.ch

* Correspondence: joan.narciso@hest.ethz.ch

+ Presented at the 1st International Electronic Conference on Food Science and Functional Foods, 10-25 November 2020; Available online: https://foods_2020.sciforum.net/.

\begin{abstract}
Cultivating ancient crops improves food security by diversifying our staple foods. An example of ancient Philippine crops is the kabog millet, an ecotype of Panicum miliaceum. Little is known about its nutritional quality; hence, the nutritional value of kabog millet was analyzed in comparison to rice and to a reference millet sourced from local supermarkets in Switzerland. We found that whole grain kabog millet has a dietary fiber and ash content almost three times of black rice, protein levels almost double of white rice and 1.5 times higher than black rice, total phenolic acid content more than double than black rice and more than five times higher than the reference millet, and a total carotenoid content that is almost 2.5 times higher than the reference millet and almost five times higher than black rice. To assess the antioxidant activity, DPPH, 2,2'-azino-bis(3ethylbenzothiazoline-6-sulfonic acid) (ABTS), and Oxygen Radical Absorbance Capacity (ORAC) were used. The antioxidant activities of the whole kabog millet were significantly higher than the reference millet in all three assays. By giving attention to underutilized, ancient crops, we are not only saving biodiversity and our planet, but we are also breathing new life into these forgotten ancient treasures.
\end{abstract}

Keywords: kabog millet; functional food; dietary fiber; ash content; phenolic acid; carotenoid; protein; antioxidant activity

\section{Introduction}

Little is known about the kabog millet, an ecotype of Panicum miliaceum, and the only known proso millet existing in the Philippines. Kabog millet once grew wild and in abundance in the mountains of Catmon, Cebu, one of the central Visayas Islands of the Philippines, from locally acquired seeds. Since there is a lack of nutritional studies for kabog millet, it is unknown how it will compare to rice. However, other millet varieties were found to have high nutritive value and comparable to wheat and rice [1]. Millet proteins are also good sources of essential amino acids except lysine and threonine, but are relatively high in methionine. In addition, millets are rich sources of phytochemicals and micronutrients $[2,3]$.

The production of the kabog millet is dwindling. It is not promoted as a profitable crop, and the government encourages cultivation of higher yielding varieties. Traditional, historical crops like kabog millet are disregarded and are often overlooked. Hence, a nutritional content analysis of kabog millet is needed to encourage farmers, consumers, and the government to consider it as an alternative to rice. We report here the nutritional quality of kabog millet compared to different rice types (white and black), and a reference millet that can be bought from local supermarkets in Switzerland. It is hoped that by doing so, the kabog millet genetic pool will be conserved for future generations, and with it, the rich cultural heritage of the Cebuanos. It will also provide livelihood to small-scale 
farmers and their families. Consumers will appreciate the global diversity of cereal crops and will have access to nutritional and sustainable food choices by incorporating kabog millet into their diet.

\section{Methods}

\subsection{Samples}

White and black rice were purchased from New Asia Market Zürich. The reference millet was purchased from Migros, a Swiss supermarket (Zürich, Switzerland). Unmilled (whole grain) kabog millet were purchased from two sources in Cebu, Philippines: (1) Mrs. Rosaflor Montecillo Estenzo, Location: Purok Tambis, Baranggay Agsuwao, Catmon, Cebu; (2) Mr. Nolito Ares, Location: Baranggay Agsuwao, Catmon Cebu. The farmers were referred by Ms. Teresa D. Ruelas and the use of the kabog millet for this research is covered by a material transfer agreement.

\subsection{Nutritional Content Analysis}

\subsubsection{Dietary Fiber, Ash, and Total Protein}

The dietary fiber (K-TDFR-200A) kit was purchased from Megazyme Ltd., and the analyses were performed according to the manufacturer's protocols. For ash analysis, 1.5 $\mathrm{g}$ was weighed for each flour sample in a porcelain crucible and the weight of the crucible with the flour was recorded. The samples were placed in a muffle furnace at $600{ }^{\circ} \mathrm{C}$ for 5 $\mathrm{h}$. The residues were weighed after cooling. The \% Ash was calculated using the following formula:

$$
\% \text { Ash }=\frac{M_{\text {ash }}}{M_{\text {sample }}} \times 100,
$$

where $M_{\text {ash }}$ is the weight of the residue after ashing in the muffle furnace; Msample is the weight of the dry flour sample before ashing.

The ground samples were sent to AgroVet-Strickhof in Lindau, Switzerland, for Dumas analysis of total $\mathrm{N}$ content. To obtain the total protein content, the $\% \mathrm{~N}$ were multiplied with 5.95 (rice samples) and 5.83 (millet samples) [4].

\subsubsection{Carotenoids}

In each 50-mL dark Falcon tube, $500 \mathrm{mg}$ of ground sample was weighed. To each tube was added $50 \mu \mathrm{L}$ of internal standard solution. The carotenoids were extracted with 1-butanol by sonication for $15 \mathrm{~min}$. The samples were stirred for $30 \mathrm{~min}$ on a magnetic stirrer. The samples were sonicated again for $15 \mathrm{~min}$, after which the samples were stirred again for $30 \mathrm{~min}$. The samples were centrifuged and the supernatant ( 1 to $1.5 \mathrm{~mL}$ ) was filtered through a hydrophilic syringe filter into an amber-colored HPLC vial. The samples were analyzed by HPLC.

\subsubsection{Phenolic Acids}

Total phenolic acids were extracted from $500 \mathrm{mg}$ of ground flour, weighed in 50-mL Falcon tubes. To each tube, $250 \mu \mathrm{g}$ of internal standard was added to spike the sample. To release esterified and bound phenolic acids, $2 \mathrm{M}$ sodium hydroxide was added, and the samples stirred for $1 \mathrm{~h}$ at room temperature. To neutralize the samples, concentrated hydrochloric acid and ethyl acetate were added to each tube, and the samples were vortexed. After centrifuging the sample for $5 \mathrm{~min}$ at $4000 \mathrm{rpm}$, the supernatant was transferred into a fresh 50-mL Falcon tube. Extraction with hydrochloric acid and ethyl acetate was repeated and the supernatants were combined. The solvent was evaporated with a gentle nitrogen stream at $60^{\circ} \mathrm{C}$. The dried samples were dissolved in $1 \mathrm{~mL}$ of HPLC eluent and sonicated. The redissolved samples were filtered through a hydrophilic syringe filter into HPLC vials and analyzed by RP-HPLC. 


\subsection{Antioxidant Assays}

DPPH, ABTS, and ORAC Assays

For the antioxidant assays, the total phenolic acid extracts were tested. The DPPH radical scavenging activity method used in this study was modified from [5]. Pyrogallol in methanol (final concentration $66 \mu \mathrm{M}$ ) was used as the positive control. After quickly mixing the antioxidant (total phenolic acid extracts or pyrogallol) and DPPH, the absorbance at $517 \mathrm{~nm}$ was recorded immediately at $0 \mathrm{~min}$ and after $5 \mathrm{~min}$. The \%radical scavenging activity (\%RSA) was calculated as follows:

$$
\% R S A=100 \times \frac{\left(A_{0}-A_{t}\right)}{\left(A_{0}-A_{p}\right)^{\prime}}
$$

where $A_{0}=$ absorbance $\left(\mathrm{DPPH}+\right.$ sample or pyrogallol) at $0 \mathrm{~min} ; A_{t}=$ absorbance $(\mathrm{DPPH}+$ sample) at $5 \mathrm{~min} ; A_{p}=$ absorbance (DPPH + pyrogallol) at $5 \mathrm{~min}$.

The 2,2'-azino-bis(3-ethylbenzothiazoline-6-sulfonic acid) (ABTS) Antioxidant Capacity Assay (KF01002) and the Oxygen Radical Absorbance Capacity (ORAC) Assay (KF01004) kits were purchased from Bioquochem (Asturias, Spain), and the ABTS and ORAC antioxidant assays were performed using the total phenolic acid extracts following the manufacturer's protocols.

\section{Results and Discussion}

The nutritional content and quality of kabog millet were determined in comparison with white and black rice, and a reference millet from a local Swiss supermarket. The parameters measured were total dietary fiber, ash, total protein, carotenoids, phenolic acids, and $\mathrm{DPPH}, \mathrm{ABTS}$, and ORAC antioxidant assay activities.

The whole kabog millet samples contained the highest amount of total dietary fiber (14-15\%). This can be attributed to the presence of the hull and the outer bran layer in the whole kabog millet. The hull and the outer bran layer are where the dietary fiber is highly concentrated [6,7]. Milling significantly decreases, among other nutrients, the crude fiber and the dietary fiber content [8]. In terms of ash content, white rice had the lowest while the whole kabog millet samples had the highest ash amount ( 4\%).

For total protein content, the rice samples had relatively low total protein content (6$8 \%)$ compared to the millet samples. The millet samples had almost double (11-12\%) the protein content of white rice. Rice is not a good source of protein, having only around $7 \%$ for white rice [9]. Among cereals and pseudocereals, quinoa and amaranth have one of the highest protein contents ( 14- 17\%) [10,11]. Millet has around $11 \%$ protein [11], which shows that the reference millet and the kabog millet can be good sources of proteins compared to rice.

For total carotenoid content, the kabog millet samples exhibited the highest total amounts of carotenoids (16-17\%), due to their lutein and zeaxanthin content, compared to the reference millet $(\sim 7 \%)$ and the rice samples $(0-4 \%)$. Carotenoids cannot be synthesized by animals, and hence, are normally obtained through the diet. Lutein and zeaxanthin are macular carotenoids that may play a role in protection against light-dependent eye damage [12]. For the total phenolic acid content, the whole kabog millet had the highest amount $(1500-1600 \mu \mathrm{g} / \mathrm{g})$, followed by black rice $(\sim 700 \mu \mathrm{g} / \mathrm{g})$ and the reference millet $(\sim 300 \mu \mathrm{g} / \mathrm{g})$.

The total phenolic acid extracts were tested for antioxidant activity using DPPH, ABTS, and ORAC assays. In the DPPH assay, the \%RSA value of black rice was comparable to those of whole kabog millet samples from sources (1) and (2), while white rice had the lowest \%RSA value. In the ABTS assay, the \%Inhibition of the ABTS radical cation was highest in the whole kabog millet samples with almost the same values for both sources (1) and (2). This was followed by black rice, the reference millet, and white rice.

In terms of Trolox equivalence antioxidant capacity (TEAC) in the ORAC assay, the whole kabog millet and black rice had comparable and the highest TEAC values ( 1400), followed by the reference millet ( 1200). White rice had the lowest TEAC among all the 
samples analyzed ( 170). The antioxidant activities of the total phenolic extracts from rice and the millet samples were analyzed through DPPH, ABTS, and ORAC antioxidant assays. The DPPH \%RSA values are comparable between the whole kabog millet and the black rice samples. This makes the phenolic acids found in red and black rice, and the whole kabog millet as effective free-radical scavengers, while in the ABTS, the whole kabog millet samples have the highest \%inhibition values. In the ORAC assay, black rice and whole kabog millet phenolics were the most effective peroxyl radical scavengers. In biological systems, peroxyl radicals are stable oxygen-centered radical species formed through autoxidation of fats. This stability enables them to diffuse to distant cellular locations [13].

\section{Conclusions}

Kabog millet, particularly the whole samples, has good nutritional quality in terms of total dietary fiber, ash, total protein content, phenolic acid, carotenoid content, and antioxidant activity by DPPH, ABTS, and ORAC assays. It can be promoted as a healthier cereal substitute to white rice.

Funding: This research was generously and kindly supported by the Future Food Initiative, ETH Zürich World Food System Center, ETH Zürich Foundation project number: ETH 2019-HE-322.

Acknowledgments: The authors would like to acknowledge Charisse T. Reyes, Teresa D. Ruelas, Rosaflor Montecillo Estenzo, and Nolito Ares for the procurement of the kabog millet; Svenja Krupp and Svenja Bendel for the technical support regarding the dietary fiber, phenolic acids, and carotenoids analyses; and Carmen Kunz for the facilitation of the Dumas analysis (protein).

\section{References}

1. Parameswaran, K.; Sadasivam, S. Changes in the carbohydrates and nitrogenous components during germination of proso millet (Panicum miliaceum). Plant Foods Hum. Nutr 1994, 45, 97-102, doi:10.1007/BF01088466.

2. Mal, B.; Padulosi, S.; Ravi, S.B. Minor Millets in South Asia: Learnings from IFAD-NUS Project in India and Nepal; Bioversity International: Rome, Italy; M.S. Swaminathan Research Foundation: Chennai, India, 2010; pp. 1-185.

3. Singh, P.; Raghuvanshi, R.S. Finger millet for food and nutritional security. Afr. J. Food Sci. 2012, 6, 77-84, doi:10.5897/AJFSX10.010.

4. FAO/INFOODS e-Learning Course on Food Composition Data. Available online: http://www.fao.org/elearning/Course/FCD/en/pdf/1151_factors_for_the_conversion_of_nitrogen_values_to_protein.pdf (accessed on 1 April 2020).

5. Zhu, D.; Sanchez-Ferrer, A.; Nyström, L. Antioxidant Activity of Individual Steryl Ferulates from Various Cereal Grain Sources. J. Nat. Prod. 2016, 79, 308-316, doi:10.1021/acs.jnatprod.5b00880.

6. Saleh, A.; Wang, P.; Wang, N.; Yang, L.; Xiao, Z. Brown Rice Versus White Rice: Nutritional Quality, Potential Health Benefits, Development of Food Products, and Preservation Technologies. Compr. Rev. Food Sci. Food Saf. 2019, 18, 1070-1096, doi:10.1111/1541-4337.12449.

7. Fernando, W. Rice as a Source of Fibre. J. Rice Res. 2013, 1, 2, doi:10.4172/jrr.1000e101.

8. Saleh, A.S.; Zhang, Q.; Chen, J.; Shen, Q. Millet Grains: Nutritional Quality, Processing, and Potential Health Benefits. Compr. Rev. Food Sci. Food Saf. 2013, 12, 281-295, doi:10.1111/1541-4337.12012.

9. Moongngarm, A. Chemical compositions and resistant starch content in starchy foods. Am. J. Agric. Biol. Sci. 2013, 8, 107-113, doi:10.3844/ajabssp.2013.

10. Koziol, M. Chemical composition and nutritional evaluation of quinoa (Chenopodium quinoa Willd.). J. Food Compos. Anal. 1992, 5, 35-68, doi:10.1016/0889-1575(92)90006-6.

11. Young, V.R.; Pellett, P.L. Plant proteins in relation to human protein and amino acid nutrition. Am. J. Clin. Nutr. 1994, 59, 1203S1212S, doi:10.1093/ajcn/59.5.1203S.

12. Stahl, W. Macular carotenoids: Lutein and zeaxanthin. Dev. Ophthalmol. 2005, 38, 70-88, doi:10.1159/000082768.

13. Marnett, L.J. Peroxyl free radicals: Potential mediators of tumor initiation and promotion. Carcinogenesis 1987, 8, 1365-1373, doi:10.1093/carcin/8.10.1365. 